\title{
Aristotle on Accidental Causation
}

\begin{abstract}
I offer a new analysis of Aristotle's concept of an accidental cause. Using passages from Metaphysics $\Delta$ and $\mathrm{E}$, as well as Physics II, I argue that accidental causes are causally inert. After defending this reading against some objections, I draw some conclusions about Aristotle's basic understanding of causation.
\end{abstract}

KEYWORDS: Aristotle, ancient philosophy, causation, commensurateness, accidental

\begin{abstract}
Well, I said, is there really nothing that can rightly be called chance or accident? Or could it be there is something that these words are appropriate for, even if it is hidden from the common folk? She said: it is in his Physics that my Aristotle has defined it, in a demonstration both brief and near to the truth. (Boethius 200I: V.I.II)
\end{abstract}

If Aristotle's distinction between accidental and non-accidental properties is central to his ontology as a whole, it is a wonder that more attention is not paid to his distinction between accidental and non-accidental causes. To be sure, the texts where one finds Aristotle mentioning the distinction are the focus of much research, but there is something incredibly important about the distinction itself that is not brought out by focusing on the usual topics that readers associate with accidental causes, topics such as Aristotle's affirmation or denial of some form of determinism or what his phrase 'always or for the most part' means or what luck and chance are. This is a pity, for, as I will argue, this distinction is vital in understanding Aristotle's theory of causation. For Aristotle, the distinction illustrates a crucial feature of causes.

This paper attempts to remedy the situation. In section I, I argue that on the basis of passages in Physics II and Metaphysics $\Delta$ and E, Aristotle took accidental causes to be causally inert. That is, Aristotle is an eliminativist regarding accidental causation. In section 2, I consider some objections to this view and use those objections to refine the eliminativist account. In section 3, I consider the implications of Aristotle's eliminativism, the most important of which is that

It is my great pleasure to thank especially Dom Bailey, whose incisive comments and encouragement made this paper immeasurably better at every stage of its drafting. I also thank Mitzi Lee, Robert Pasnau, Sydney Penner, Brian Reese, Tad Schmaltz, Rachel Singpurwalla, Nathanael Stein, C. C. W. Taylor, Damon Watson, and the anonymous referees at JAPA for their written feedback at various stages, as well as audiences at the 20I 5 Society for Ancient Greek Philosophy meeting and the 2016 Central Division APA meeting. 
he identifies causes in a very austere but precise manner. For him, causes must be commensurate with their effects, in a sense to be explained below.

\section{Pickwickian Causes}

Aristotle frequently talks of two items being accidentally conjoined, and his examples of these accidental unities are familiar: seated Socrates, cultured Corsicus,

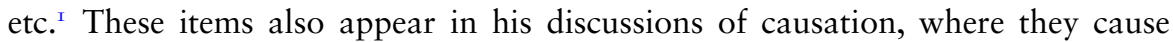
certain effects and are the effects of certain causes, and it is when these various accidental unities enter into causal interactions that accidental causation arises. The unities involved in causation include both combinations like Socrates and being seated, and combinations like the simultaneous presence in the marketplace of a debtor and his creditor. Given these different types of unities, accidental causation has various subspecies depending on what type of accidental unity plays a causal role-for example, certain subspecies are dubbed 'luck' and 'chance' based on what kind of accidental unity is involved-but my primary concern here is accidental causation in the broadest sense, and I will consider multiple types of accidental unities entering into causal interactions. ${ }^{2}$

One well-known passage that deals with accidental causation speaks of Polyclitus' sculpting:

[TI] And some causes are accidental, or in its genera; thus the cause of a statue is in one way a sculptor and in another Polyclitus, in that being Polyclitus is accidentally conjoined to the sculptor. (Physics II.3, I95a32-35, trans. Charlton [I970], with minor alterations)

Interpretively, I do two things in order to impose uniformity on the texts I consider here. First, some translators render $\kappa \alpha \tau \grave{\alpha} \sigma v \mu \beta \varepsilon \beta \eta \kappa \grave{\zeta} \varsigma$ variously as 'coincidental', 'incidental', and 'accidental'-I use 'accidental' throughout, and this is not meant to rule out some subtlety implied by the variable terminology of others. Second, while Aristotle typically uses $\kappa \alpha \tau \grave{\alpha} \sigma v \mu \beta \varepsilon \beta \eta \kappa \grave{o} \varsigma$ to pick out accidental causes, he varies terminology in speaking of those causes contrasted with accidental causes:

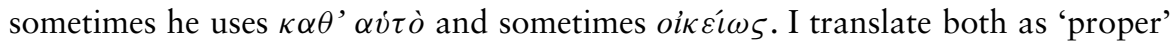

I These sorts of conjunctions, dubbed 'kooky objects' by Matthews (I982), have been the focus of much research; see Brower (2010), Cohen (2008), Matthews (I982, I990), and Peramatzis (20II). It should be noted that there is disagreement regarding the status of kooky objects—see, e.g., Shields (I999: I 55-7I)—and those who disagree likely would prefer to explain the basics of accidental causation in a manner different from my exposition in this section. I do not think that my argument presupposes either option, but for the sake of economy, I write as if Matthews has the right reading-the exposition can be translated into the dissenting view easily enough.

2 There is a good deal of literature dealing with accidental causes in Aristotle, especially in connection with luck and chance. The following contain helpful discussions: Allen (2015), Annas (I982), Charles (I984, 2003), Charlton (I970), Denyer (I993), Dudley (20I2), Everson (I997), Fine (I98I), Frede (I985, I992), Freeland (I99I), Hankinson (I998, 2002), Heinaman (I985), Ide (I993), Irwin (I988), Johnson (2006), Judson (I99I), Kelsey (2004), Kirwan (I993), Lennox (I984), Leunissen (2010), Lorenz (2015), Meyer (I992, I993), Rossi (20II), and Sorabji (I980). 
hereafter. Now, given that accidental causation arises when some accidental unity plays a causal role, some parts of the unity are proper causes, and some are accidental causes. This is just what we find in [TI]: Polyclitus and the sculptor are accidentally conjoined, and in one way the cause of the statue is Polyclitus, but in another way the sculptor, rather than Polyclitus, is the cause of the statue.

In order to elaborate more clearly the difference between proper and accidental causes, consider the following two sentences that concern the situation laid out in [TI]:

(I) The sculptor is an efficient cause of the statue.

(2) Polyclitus is an efficient cause of the statue.

Now, I formulate (I) and (2) without explicitly mentioning accidental or proper causes, opting instead to formulate them in terms of efficient causation. I do this for two reasons. First, it is all too easy to say that Aristotle takes Polyclitus to be an accidental cause of the statue and the sculptor to be the proper cause of the statue, for that is what we find in [TI]. If we are to elaborate Aristotle's theory of accidental causation any further, (I) and (2) cannot be formulated merely in terms of accidental and proper causes. Second, in [TI], the type of causation at stake is efficient. This is no idle point, since the distinction between accidental and proper causes cuts across the more familiar fourfold distinction in causes; see, for instance, Physics II.3, I95a27-32, where Aristotle claims that, along with the distinctions between actual and potential and general and singular causes, the distinction between accidental and proper causes is applicable to each of the four causes. Now, in many passages, Aristotle explains efficient causation in terms of the activity of professionals such as sculptors, doctors, or builders-they are his preferred examples of efficient causation. ${ }^{3}$ So I take it that $\left[\mathrm{T}_{\mathrm{I}}\right]$ clearly concerns efficient causation. As we will see below, there are several useful accounts of accidental causation throughout Aristotle's works that concern efficient causation, accounts that help us get a grip on (I) and (2).

Of course, given that (I) is about professionals efficiently causing what is characteristic for them to make, Aristotle is clearly committed to it. I see no other way of understanding his repeated use of such examples for explaining efficient causation. On the other hand, we have good evidence that (2) is something he would deny. In some of his extended treatments of accidental causation, he claims that items accidentally conjoined either to proper causes or to proper effects do not factor into causal interactions. More specifically, he makes the following twin claims: (i) relative to proper effects, accidental causes efficiently cause nothing at all; and (ii) relative to proper causes, accidental effects are not efficiently caused at all. ${ }^{4}$ If this is Aristotle's considered view, it is simply false that in the [TI] example

3 E.g.: Topics II.2, I Ioa I4-22; V.7, I36b33-I 37a8; Physics II.I, I92b24ff.; II.3, I95b22-25; De generatione

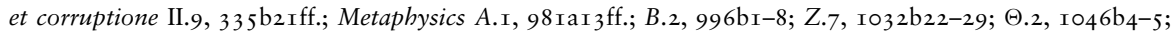
and $\Theta .8$, 1050a24ff.

4 Mueller (200I: 70) might put forward a similar tack, in saying that 'The reason why people's desires, and not luck, explain their meeting is that their desires brought about the meeting, and luck did not'. This remark is a throwaway, though, and the idea that, for Aristotle, luck lacks causal efficacy is neither clarified nor defended. 
Polyclitus is an efficient cause of the statue, for Polyclitus is an accidental cause relative to a proper effect. For the rest of this section, I will focus on the texts that support (i) and (ii).

I begin with a passage from Metaphysics $E$ that evinces (ii), the idea that accidental effects are not efficiently caused by proper causes:

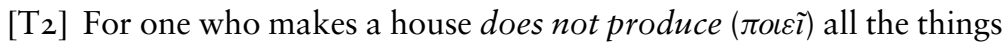
which coincide in the house that is coming to be, for they are indefinite. There is nothing to prevent the house he has produced being pleasing to some, harmful to others, beneficial to others, and different from everything that is; but the art of house-building is not productive of any of those things. (E.2, I026b6-1o, my emphasis; trans. Kirwan [1993], with minor alterations) ${ }^{5}$

In order to understand [T2], we must recall two points. First, not only do accidental unities factor into causal interactions as causes but also as effects. A house, say, figures in an accidental conjunction: houses have some features contingently and thereby accidentally. Insofar as a house is a thing that provides shelter, it could have or fail to have any number of aesthetic qualities and still be a house, such that its sublime (or revolting) look is accidentally conjoined with it. Second, when Aristotle considers what it is that a builder produces, this is a way of considering what the

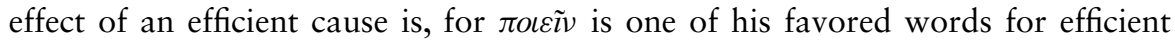
causing. In Physics II.3, I94b3 I, he gives a general characterization of efficient causes, saying that 'in general, [the primary source of change is] that which makes

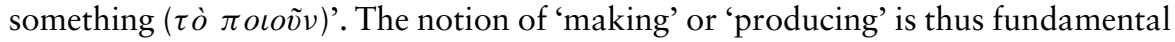
to his theory of efficient causation. So if there is any sense in which a builder is an efficient cause of the house, there must be a sense in which he made it.

At the end of [ $\left.\mathrm{T}_{2}\right]$, Aristotle states that whatever is accidentally conjoined to a proper effect is not caused by the proper cause. This is (ii), and it is a stronger claim than the one he makes at the beginning of the passage where he states that not all accidental effects are caused by the proper cause, for that is quite compatible with the proper cause causing all but one of them. The stronger claim, at the end of the passage, is much more bold-anything that is accidentally conjoined to that effect, i.e., any one of 'all of the things which coincide in the house that is coming to be' is not produced or made by the house builder. That is, $\left[\mathrm{T}_{2}\right]$ is evidence that relative to proper causes, accidental effects are not efficiently caused.

This is a consequence so startling that one might tarry over [T2] in hopes of finding something, anything, that might absolve Aristotle of this idea. For example, you might think that the referent of 'those things' at the end of [T2] is not, as I take it to be, accidents in general, but rather only the accidents mentioned explicitly in [ $\left.\mathrm{T}_{2}\right]$-being pleasing, being harmful, and being beneficial. Put another way, a plausible but weaker reading of $\left[\mathrm{T}_{2}\right]$ is that although the house builder does

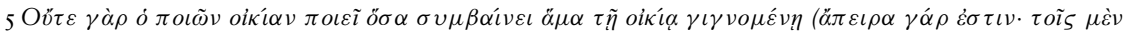

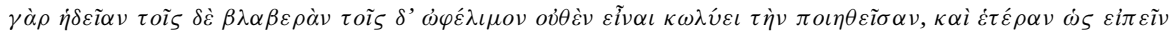

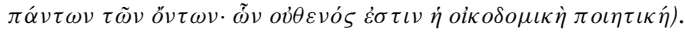


not produce pleasure or benefit, she might very well produce other accidents. On this weaker reading, [T2] fails to evince (ii), but the reading also ignores what is conversationally implied in the passage: an arbitrary selection of accidents of a house will select items not produced by the art of house building, and because the group of accidents mentioned in [ $\left.\mathrm{T}_{2}\right]$ is arbitrary, no accident whatsoever is produced by the art of house-building. Moreover, the rider before the final clause of the passage, 'different from everything that is', evinces Aristotle's concern with accidents in general. Surely, a number of houses are pleasant to look at, confer benefits, etc. So the three accidents Aristotle explicitly mentions are not enough to make the house in [ $\left.\mathrm{T}_{2}\right]$ different from everything that is. Likely, then, Aristotle has more accidents in mind than merely those explicitly mentioned, and hence the passage shows a commitment to (ii).

There may be another difficulty, however, with using [T2] to attribute (ii) to Aristotle, for Aristotle there seems to go back and forth as to what it is that produces or fails to do so. At the beginning of the passage, Aristotle identifies the house builder $(\dot{o} \pi \circ \tilde{\omega} v$ oiki $\iota v)$ as that which does not produce the accidents of the house. But at the end of the passage, Aristotle identifies the art of house

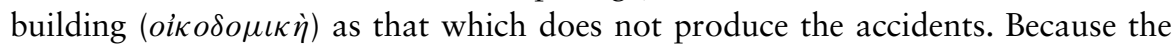
claim at the end of [ $\left.\mathrm{T}_{2}\right]$ is stronger than the claim at the beginning, and because (ii) is evinced only by the stronger claim, there may be conceptual space available for giving Aristotle the claim that the house builder is an efficient cause of some, though not all, of the accidents of the house, and also that the art of house building is not an efficient cause of any accident-perhaps because the art of house-building is not productive of anything or perhaps because there is a difference between the dispositional property being productive and the categorical property being produced. So, at least, one might object.

Finding this conflation in $\left[\mathrm{T}_{2}\right]$ is not altogether surprising, for Aristotle elsewhere does seem to vacillate between making the art the efficient cause and making the artisan the efficient cause. For instance, he identifies the art of house building as a proper cause of houses in Physics II.5, I96b26, but only a few lines later (I97bI4I 5 ) he identifies the house builder for this same role-all the while ignoring any complications that might arise from this dual classification. Still, I am hard-pressed to find the maneuvering above a more persuasive depiction of Aristotle's thought in [T2] than (ii). Finding a difference between being productive and being produced in Aristotle is far from easy because some texts suggest that Aristotle would deny that there is such a difference. For example, Metaphysics $\Delta . \mathrm{I}_{2}$ begins with Aristotle's avowal that a capacity or power is 'what originates a change or alteration in another thing' ( IOI 9a I 5-I6). Aristotle does not say that capacities are what can change, but that they are what does change, riding over the sort of distinction one might try to find within [ $\mathrm{T}_{2}$ ] between being productive and being what produces. Of course, Aristotle's grammar seems to show some sort of distinction, but texts such as $\Delta$.I 2 make it doubtful that we should deploy it in giving a philosophical interpretation of $\left[\mathrm{T}_{2}\right]$. More likely, then, Aristotle's use of now the house builder, now the art of house-building, is not the introduction of a distinction between being productive and being produced; rather, it is simply a way of denoting the proper efficient cause. If this is how [T2] works, then it is evidence for attributing (ii) to Aristotle. 
Since [ $\mathrm{T}_{2}$ ] deals with items accidentally conjoined to the proper effect of some cause, claiming that they are not caused by the proper cause, it evinces one of the twin claims. Regarding the other twin claim, (i), there is every reason to think that in his most conscious reflections on the matter, Aristotle would have been willing to transfer what he says about accidental effects not being caused by proper causes to accidental causes not having any proper effects. To be sure, we do find a parallel passage of this sort, one dealing with a species of accidental cause, namely, luck:

[T3] There is a way in which things come to be as the outcome of luck: they come to be by virtue of accident, and luck is an accidental cause. But strictly ( $\dot{\alpha} \pi \lambda \tilde{\omega} \varsigma)$, it is the cause of nothing. As in the case of a house the cause is a builder, but by accident a flute-player, so in the case of the man who came and recovered the money, but did not come for that purpose, an unlimited number of things can be accidental causes. (Physics II.5, I97aI2-17, my emphasis; trans. Charlton [I970])

Here, Aristotle claims that, strictly, luck does not cause anything. Moreover, he puts this feature of luck right next to his example of the builder building. Putting these cases side by side gives, at the very least, the implicature that the cherished case of the builder making a house has the same features as the case of luck: items accidentally conjoined to the house builder do not cause the proper effect, the house, at all. ${ }^{6}$ Neither the house builder's being cultured nor being tanned nor even being Polyclitus is productive of the house-only the house builder makes the house. Thus, [ $\left.\mathrm{T}_{3}\right]$ supports Aristotle's commitment to the other of the twin claims, the idea that, relative to proper effects, accidental causes make or produce nothing at all.

The support I find in [ $\left.\mathrm{T}_{3}\right]$ is not without difficulties, for one might hesitate to read $\left[\mathrm{T}_{3}\right]$ in this way on the basis of Aristotle's deployment of $\dot{\alpha} \pi \lambda \tilde{\omega} \varsigma$, which is rendered as 'strictly'. Perhaps, it might be thought, luck is a cause in some looser sense, such that $\left[\mathrm{T}_{3}\right]$ does not straightaway support (i). This is an important objection in that it goes right to the heart of the matter: the point at issue in $\left[\mathrm{T}_{3}\right]$ surely hinges on what $\dot{\alpha} \pi \lambda \tilde{\omega} \varsigma$ means there. But other texts do seem to support (i), and to do so without using $\dot{\alpha} \pi \lambda \tilde{\omega} \varsigma$, such that whatever subtleties might be introduced by that term in [ $\left.\mathrm{T}_{3}\right]$ do not prevent the passage from being evidence of (i). If we keep in mind that Aristotle claims that his distinction between proper and accidental causes is not limited to the domain of efficient causation, we might expect to find passages elaborating accidental causes in other modes of causation. And indeed we do, for Aristotle's example of the internal angles of a triangle summing to two right angles supports attributing (i) to him in the context of formal causation:

6 I use 'implicature' because lucky causes are merely a species of accidental cause, and thereby it is compatible with luck being the cause of absolutely nothing that some nonlucky but still accidental causes are causally efficacious. While this is logically possible, it would be the burden of someone determined to think this to furnish texts; meanwhile, my interpretation, on which lucky causes cause nothing because they are accidental causes, is coherent, plausible, and well-supported. 
[ $\left.\mathrm{T}_{4}\right]$ Things are called accidental in other ways also, as for instance whatever holds good of each thing in its own right without being in its substance, as for instance possessing two right angles ('having $2 \mathrm{R}$ ') does of a triangle. These admit of being eternal, but the former do not. (Metaphysics $\Delta .30$, 1025a30-b2, trans. Kirwan [I993], with minor alterations)

Aristotle here claims that every triangle has $2 \mathrm{R}$, and eternally so. Yet, as he also claims, having $2 \mathrm{R}$ is not part of the substance of a triangle, i.e., of what it is to be a triangle. Note that Aristotle does not say that having $2 \mathrm{R}$ is not part of the substance of a triangle $\dot{\alpha} \pi \lambda \tilde{\omega} \varsigma$; rather, he only says that it is not part of the substance, thus avoiding the difficulties put to $\left[\mathrm{T}_{3}\right]$. More precisely, in [ $\left.\mathrm{T}_{4}\right]$ Aristotle is committed to the notion that a specification of what it is to be a triangle, its form, will not mention the property of having $2 R$. As such, even though having $2 R$ is necessary and sufficient for being a triangle-something that has $2 \mathrm{R}$ will always be a triangle and never anything else-nevertheless, having $2 \mathrm{R}$ is not part of a triangle's formal cause and thereby does not cause that which is the actualization of the formal cause. It is another example of something that, insofar as it is accidental to a proper cause, does not cause what the proper cause does.

The point that is more clearly put in $\left[\mathrm{T}_{4}\right]$ coheres well with my reading of $\left[\mathrm{T}_{3}\right]-$ both texts support attributing to Aristotle the claim that, relative to proper effects, accidental causes make or produce nothing at all. It is on the basis of this coherence that $\mathrm{I}$ take $\left[\mathrm{T}_{3}\right]$ and $\left[\mathrm{T}_{4}\right]$ as supporting $(\mathrm{i})$, and $\left[\mathrm{T}_{2}\right]-\left[\mathrm{T}_{4}\right]$ as constituting evidence that Aristotle is committed to both of the twin claims. Given this commitment, (2) cannot be true for Aristotle: in $\left[T_{I}\right]$, Polyclitus is an accidental cause relative to the proper effect, the statue, so Polyclitus cannot very well have been an efficient cause of the statue. In short, there is a difference in truth value between (I) and (2), a difference that brings into relief the fact that, for Aristotle, accidental causes are causally inert. In the next section, I develop this account of accidental causation by considering an objection to it.

\section{What Accidental Causes Are}

The analysis I am proposing is simple enough: only proper causes are causally efficacious, whereas accidental causes are causally inert. Accidental causes are merely items that are accidentally conjoined to proper causes. To be sure, this is not to say that something that is an accidental cause is never causally efficacious, for an accidental cause will be accidental only relative to certain contexts. So the fact that something is an accidental cause and therefore is causally inert in one context does not prevent it from being a proper cause, and therefore causally efficacious, in a different context. For example, being pale is causally inert relative to producing a house, but relative to producing a perception of paleness it is causally efficacious. Still, in the context in which an accidental cause is accidental, no accidental cause is causally efficacious. Hence, I call my understanding of accidental causes the eliminative approach. 
Attributing an eliminative account to Aristotle is quite surprising. Indeed, the eliminative account is orthogonal to the usual ways in which accidental causes are understood. Previously, accidental causes have been thought either to fail to explain their effects or to fail to cause their effects always or for the most part. ${ }^{7}$ Now, eliminativism regarding accidental causes is compatible with either of these typical approaches: failing to be a cause of some effect is sufficient for both failing to explain some effect and failing to cause some effect always or for the most part. Nevertheless, attributing eliminativism to Aristotle is surprising because accidental causes are normally taken to be causally efficacious. Consider Charles's following elaboration of accidental causes:

If a substance's actualization causes an effect when described in one way, it will do so when described in another.... In giving 'the [proper] cause', Aristotle aims at giving the description of the substance which is most specifically or directly connected with the actualization which is causally efficacious. By contrast, 'the accidental cause' will be given using a description of the substance which is not connected in this way with the relevant actualization. (Charles I984: 45-46; my emphasis) ${ }^{8}$

Charles's remark that an actualization causes its effect, whether the description of the actualization is explanatory or not, clearly entails that he takes Aristotle as giving causal efficacy to accidental causes. Dudley takes a similar stance, claiming that 'the cause of the statue is the sculptor, but equally the cause is Polyclitus' and that 'while [accidental causes] are true causes, the kind of explanation sought by an enquirer usually means that it is unnecessary to mention accidental causes at all' (Dudley 20I 2: 368). Hankinson, too, attributes efficacy of accidental causes to Aristotle insofar as Hankinson says that, in connection with accidental causes, 'If my only concern is to designate the cause of some outcome, I need not worry whether I pick it out qua author of the result in question. I may refer to the sculptor as the man in the beret if I want to' (Hankinson I 998: I33). Hankinson would have it, then, that designating Polyclitus as the maker of the statue in $\left[\mathrm{TI}_{\mathrm{I}}\right]$ is perfectly fine, such that (2) is true and that generally accidental causes are efficacious. Finally, Johnson suggests an example similar to that found in [TI] where a sculptor who also happens to be a guitar player makes a statue, stating that '[in this case] a guitar player will be a cause of the statue', showing a commitment to (2) being true

7 On the former, representative are Annas (I982: 32I-22), Charles (I984:45-46), Dudley (20I2: 368 ), Irwin (I988: I04), and Johnson (2006: 60). On the latter, see Frede (I992: 43-5I), Judson (I99I: 82-89), and Meyer (I992: 799). Note also that the usual approaches are not mutually exclusive and may even be interdependent, as suggested by the fact that some interpreters use the two in conjunction. See, e.g., Hankinson (I998: I33, I39-40).

8 It should be noted that Charles's understanding of 'relevant' in this case might not be captured entirely with 'explanatory'-his elaboration relies on the notions of direct or specific connection, as well as appropriateness (1984: 46-47), and that is enough, I think, to classify his reading as an explanatory, rather than frequency, approach. But in the end, it does not matter for my purposes whether he is clearly an explanatory or frequency theorist: my aim is to show that the consensus that accidental causes are causally efficacious should be revised, and Charles very clearly is a member of that consensus $\left(45^{-46}\right)$. 
for Aristotle, and giving to Aristotle the idea that accidental causes are efficacious (Johnson 2006: 60).

These attributions are likely based on texts such as [TI]—recall that there, Aristotle claims that Polyclitus is a cause of the statue 'in a way', and elsewhere Aristotle makes similar claims about accidental causes being causes in some sense or other; see, primarily, Physics II.6, I 98 a Iff. It is, perhaps, these sorts of claims that suggest attributing (2) to Aristotle and generally taking accidental cause to pick out something causally efficacious. How, then, is the eliminative account, which denies the truth of (2) and the general efficacy of accidental causes, supposed to explain Polyclitus being a cause 'in a way'?

It is possible, of course, that the passages are just flatly inconsistent or that Aristotle changed his mind between writing these various parts of Physics and Metaphysics. But there is an explanation, I think, that makes these passages consistent. In $\left[\mathrm{T}_{\mathrm{I}}\right]$, Aristotle says that there is a way in which Polyclitus is a cause and a way in which the sculptor is a cause and more generally that proper causes and accidental causes can be spoken of in various ways, but he does not elaborate therein how these ways are to be understood. ${ }^{9}$ For that, we have to consider one more passage, again, from Metaphysics E:

[T5] and it is accidental that a house-builder heals somebody, because it is characteristic of a doctor, not a house-builder, to do that, but it was accidental that the house-builder was a doctor; and a confectioner, aiming to give pleasure, might produce health in somebody, but not by virtue of his culinary [art]—-hence we say it was an accident, and in a way he produces [health], but strictly he does not. (E.2, I026b37-IO27a5, trans. Kirwan [I993])

When the confectioner produces a sweet - that is, when a sweet is efficiently caused by a confectioner-anything that is accidentally conjoined to the proper effect, the sweet, is not strictly produced by the confectioner. But in a way we can still say that this accident was produced by the confectioner: just as a house-builder heals because she is accidentally conjoined with the art of medicine, so too does the confectioner produce what is healthy because health is accidentally conjoined to the sweet. This feature of the relationship between the confectioner and her effects is the key to understanding how Polyclitus can be an accidental cause of a statue without (2) being true and how, strictly, luck does not cause anything: 'accidental' has, for Aristotle, at least one use as what, following Geach, we call an attributive adjective.

The concept of an attributive adjective goes back at least as far as the late medievals. John Buridan, for example, devotes some of his massive Summulae de dialectica to alienans adjectives, terms that do not preserve the status of other

${ }_{9}$ Ross (1936: 519) also takes the difference between accidental and proper causes to hinge on the different senses of $\kappa \alpha \tau \dot{\alpha} \sigma v \mu \beta \varepsilon \beta \eta \kappa \grave{\zeta}$ and $\kappa \alpha \theta$ ' $\alpha \dot{v} \tau \grave{o}$, stating that accidental causes have 'no real share in the causation of [a proper effect], and it is only by a façon de parler that [an accidental cause] can be said to cause at all'. He does not, however, elaborate how these senses should be understood, as I do below. This is no surprise, as he is commenting only on Physics, but it does illustrate the need to look to diverse parts of Aristotle's corpus to provide a theory of accidental causes. 
terms to which the former are appended - see Summulae de dialectica 4.6.4 (Buridan 200I: 30I). Geach dubs these types of adjectives 'attributive adjectives' and explains the notion as follows. ${ }^{\mathrm{IO}}$ Attributive adjectives are contrasted with predicative adjectives: when a predicative adjective such as 'red' is used in a predication such as 'this book is red', the predication logically divides into two further predications, namely 'this is a book' and 'this is red'. Hence a red book is a kind of book. On the other hand, 'forged', in the sense applicable to counterfeiters, is an attributive adjective such that a predication such as 'this banknote is forged' cannot be logically divided into two further predications-a forged banknote is no kind of banknote, it is a forgery. But this is not confusing or contradictory, it just points to 'forged banknote' picking out something that is not a banknote.

Aristotle's usage of 'accidental' sometimes manifests features characteristic of attributive adjectives. For example, in Posterior Analytics II.8, 93a24-26, we find the following: 'When we know $(o l \delta \alpha \mu \varepsilon \nu)$ accidentally that something exists, necessarily we have no grasp on what it is-for we don't even know ( $l \sigma \mu \varepsilon v)$ that it exists'. Each use of 'know' renders a form of $o \tilde{i} \delta \alpha$, such that Aristotle seems to be saying that one can accidentally know 'the that', some fact, without knowing the fact. That is, it can be true that one accidentally knows, in the sense given by

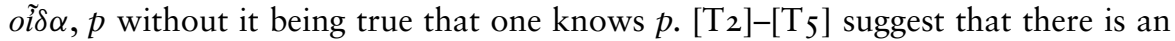
additional attributive usage in the context of causation. Just as a forged banknote is no kind of banknote, so too an accidental cause is no kind of cause: 'accidental cause' picks out something that is not itself a cause, but is accidentally conjoined with a cause. ${ }^{\text {II }}$ Today, of course, we use 'accidental' in the predicative sense-an accidental baby is, indeed, a baby-and by no means am I saying that Aristotle always uses 'accidental' attributively. But the texts above point to an attributive usage in the context of causation.

With the understanding that, in the context of causation, 'accidental' has an attributive usage for Aristotle, the $\left[\mathrm{T}_{\mathrm{I}}\right.$ ] passage can be shown to be consistent with the eliminative account: accidental causes are not causally efficacious, nor are accidental effects causally effected, such that (2) does not have to be affirmed. However, 'Polyclitus is an accidental cause of the statue' is still true, as is 'the wholesomeness of the sweet is an accidental effect of the confectioner'-they are true because Polyclitus and the wholesomeness of the sweet are both accidentally conjoined to the proper cause and the proper effect in each causal interaction. On the eliminative account, it is still true that Polyclitus is an accidental cause, we simply cannot infer from this that Polyclitus is a cause.

Io The examples I use below are Geach's; see Geach (I956) and more recently Thomson (I997) for more on the distinction between predicative and attributive adjectives.

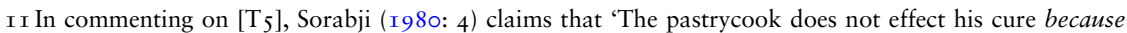
he is a pastrycook'. This could cohere with the view I am suggesting. But Sorabji's statement is syntactically ambiguous, as is often the case with 'not . . . because' locutions: he could be saying 'the pastrycook does not effect the cure at all, and this is so because he is a pastrycook',; or he could be saying 'the pastrycook did, in fact, effect the cure, but this is not because he is a pastrycook; rather, it is because he is also a doctor'. (Compare: 'he did not answer the phone because the bath was running'.) On the former interpretation, Sorabji's reading coheres with what I am advancing, but on the latter interpretation—perhaps the more likely of the two-Sorabji's reading is inconsistent with mine. 
The eliminativist can, then, give a coherent reading of these passages. Aristotle can perfectly well affirm that accidental causes such as Polyclitus do not, in the contexts in which they are accidental, make or produce anything, unlike a proper cause, and that accidental effects, in the contexts in which they are accidental, are not made or produced, unlike a proper effect. And he can perfectly well affirm that even though Polyclitus did not make the statue, he is an accidental cause of the statue. This way of explaining the compatibility of [TI] and the eliminative account also dovetails nicely with Aristotle's broader goals in Physics II.4-6: there, he is trying to give an account of luck and chance that incorporates generally held beliefs on the topic. The eliminative account, in conjunction with the notion that 'accidental' sometimes works as an attributive adjective for Aristotle, gives a framework according to which both those who say there is no such thing as luck as well as those who say some things are the outcome of luck speak well. The former because luck is, in every context, an accidental cause and thereby luck is causally inert; the latter because luck is, in every context, conjoined to something that is causally efficacious and thereby it is true to say that 'luck is an accidental cause of X'.

In the next section, I discuss the ramifications of this reading. Far from being an extremist or fringe understanding of causation, this understanding of accidental causes and effects is a welcome result in that it enables us to grasp more easily Aristotle's own views on causation.

\section{Identifying Causes}

If I am correct that for Aristotle accidental causes are not causally efficacious and that accidental effects are not causally effected, then we are in a position to appreciate Aristotle's theory of causation more broadly. One implication of the eliminative account is that there is only one causal relationship for Aristotle, namely, the relationship that holds between proper causes and proper effects. This is not to deny that Aristotle was a causal pluralist, for the distinction between proper and accidental causes cuts across the distinction between efficient, final, formal, and material causes. However, when considering accidental efficient causes or accidental formal causes, and the like, Aristotle has it that those accidental causes are not efficacious, nor are accidental effects effected, so for a given context the only causal relationship that is available is the one that holds between proper causes and proper effects.

In fact, this provides an additional basis for his distinction between proper and accidental causes in general. In $\left[\mathrm{T}_{4}\right]$, we are given a rehearsal of the house-builder example, and the house-builder's being a flute-player is said to be accidental to this causal relationship. The reason for this is that, relative to the causal process of a house-builder making a house, being cultured is completely contingent-the house builder could produce a house while being either cultured or uncultured. Similarly, in [ $\mathrm{T}_{2}$ ] we have the same process of a house builder making a house, and as Aristotle notes, it is completely contingent what aesthetic properties accidentally conjoin to the house a house builder makes-the house builder could produce a house that is either sublime or revolting, as neither of these aesthetic qualities changes the fact that she has produced a house. In general, then, accidental causes and accidental 
effects are simply items that are contingently conjoined to the causal interaction, such that the causal interaction would still be the type of interaction it is with or without them. It seems, then, that accidental causes are accidental because they are only contingently conjoined to proper causes, and similarly accidental effects are accidental because they are only contingently conjoined to proper effects. That is, accidental causes are not causes because they are not necessary for the proper effect to be produced, and accidental effects are not effects because they are not necessary for the proper cause to be causally efficacious. ${ }^{\mathrm{I2}}$

Put another way, the eliminative approach highlights the role of modal concepts in the identity of a proper cause. If accidental causes are not causes because they are not necessary for their effects, then proper causes must in fact be necessary for their effects; if accidental effects are not necessary for their proper causes-or as we typically say today, if proper causes are not sufficient for their accidental effectsthen proper causes must in fact be sufficient for their proper effects. This claim about proper causes being sufficient for their effects is one with which most would agree, but that proper causes are also necessary for their proper effects, i.e., that proper causes contain no causally irrelevant ingredients, is not a point generally appreciated. Previous approaches to understanding Aristotle's notion of proper causation do not, at any rate, seem to have taken proper causes to be necessary for their proper effects, but it becomes much more salient on the eliminative camp's understanding of accidental causes.

It might be thought that the eliminative camp's understanding of Aristotle renders his account of causation rather austere: the only causes there are, are proper causes; whether or not something is a cause is thus constrained by what effect it has, and even then, things contingently connected to a cause are not themselves causes of the cause's effect. These constraints drastically winnow out the candidates that might play the role of 'cause'. Nevertheless, these constraints on causation entail a commitment for Aristotle's general theory of causation that is philosophically interesting: it is a theory in which causes are commensurate with their effects.

Popularized by Audi (2013), Oddie (2013), and Yablo (1992), causal commensurateness is a constraint on cause-effect relationships that philosophers today find useful for capturing the intuition that causes are difference makers. Briefly, causes must be commensurate with their effects such that they occupy the right position in logical space relative to their effects, and the right position is one where their presence is both necessary and sufficient for their effects. Typically, this is explained by way of the following sort of example. Say that Bob is having a stroll in Pamplona, wearing a burgundy shirt. Unbeknownst to him, the color of his shirt has caused a bull to charge. Now, we ought not call the determinate shade of red, burgundy, the cause of the bull's charge, since the bull also would have charged at a scarlet or maroon shirt. The burgundy of the shirt is not necessary for the bull's

I 2 Aristotle's concept is even more fine-grained than this: as seen in [ $\left.\mathrm{T}_{5}\right]$, having $2 \mathrm{R}$ is necessary and sufficient for being a triangle, and yet having $2 \mathrm{R}$ is accidental, not part of the substance of triangles. Only candidates that are both necessary and sufficient for their effects can be causes-but even then, some candidates still fail to be causes. Nevertheless, hereafter I will set aside cases of necessary accidents and focus on accidental causes (and effects) that are only contingently connected with proper causes (and effects). 
charging, so it cannot be the cause of the charge. But we also must take care not to generalize too much and say that it was merely Bob's shirt being colored that caused the bull to charge since only red-colored shirts are sufficient for bulls' charging, not green or blue shirts. Thus, the redness of Bob's shirt, and not its coloredness or burgundyhood, occupies the correct position in logical space to be the cause of the bull's charge: it is determinate enough to be sufficient for its effect while not being so determinate as to be rendered unnecessary for its effect.

I submit that my reading of Aristotle's theory of proper causes shows his commitment to causal commensurateness. While it might be thought that finding commensurateness in Aristotle is anachronistic, this is somewhat hasty. There is evidence that commensurateness features in Plato's Phaedo (Bailey 20I4). And that Aristotle was committed to some form of constraint between causes and effects is hardly deniable; De generatione et corruptione I.7, 323 b28-33, is a clear example of this:

\begin{abstract}
Nothing dislodges another from its nature unless both are either contraries or from contraries. But since producing and being produced ( $\pi \alpha ́ \sigma \chi \varepsilon \iota \nu \kappa \alpha i ̀ ~ \pi o \iota \varepsilon \tilde{\nu})$ ) belong naturally, not to any old thing, but only to things which have contrariety or are contraries, agent and patient

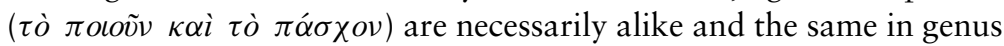
but unlike and contrary in species. (Trans. Williams [I982], with minor alterations)
\end{abstract}

Producing is, of course, efficient causation, and according to this passage, it is constrained in the following manner. The efficient cause of a production must be similar in genus to, but different in species from, that on which the efficient cause acts. The heating of some water by a fire, for instance, abides by these constraints: the fire and the water fall under the same genus in that they are both bodies, but they differ in species in that the fire is hot while the water is cold. If the water were already as hot as the fire, there would be no causal interaction, for the water and fire would not be distinct in species. Equally, there would be no causal interaction between the fire and, say, a noncorporeal item such as a mathematical object. The fire has to occupy the correct position in logical space, with respect to what it acts on, in order for it to be the cause of some heating.

This constraint is not quite a commensurateness constraint, in that it constrains what an efficient cause acts on, and not what an efficient cause ends up producing. But that Aristotle was committed to causal commensurateness in particular is shown by the austere stance, evinced by $\left[\mathrm{T}_{3}\right]$ and $\left[\mathrm{T}_{4}\right]$, he takes up regarding accidental causes. Commensurateness involves two constraints, that causes be both (i) necessary and (ii) sufficient for their effects. For Aristotle, only certain items are proper causes-anything that could obtain or fail to obtain alongside the causal interaction is not a proper cause, that is, anything unnecessary for the obtaining of the causal interaction is not a proper cause. Given also that the only causes there are, are proper causes, Aristotle's notion of cause broadly satisfies (i). Moreover, what a proper cause is, is settled with respect to its proper effect-a house builder is 
only the proper cause of a house and not, say, a statue. This connection between the identity of proper causes and proper effects ensures that proper causes are sufficient for their proper effects: what it is to be such a cause is to be sufficient for its effect. And again, given that the only causes there are, are proper causes, Aristotle's notion of cause broadly satisfies (ii). In general, then, Aristotle seems to say that something is a cause, strictly, if it is both sufficient for a proper effect and does not include any causally unnecessary ingredients-with the result that his notion of cause entails his commitment to commensurateness.

Causal commensurateness is not a feature of Aristotle's theory of causation that has yet been noticed. But the importance of this feature must be emphasized, for the claim that Aristotle's causes are commensurate is extremely potent. Commensurateness helps to explain certain established features of Aristotelian causal interactions, for instance, their stability or durability (Meyer I992: 802). More important, it sheds light on Aristotle's understanding of causes at a basic level. The distinction between proper and accidental causation applies to each of the traditional four causes, such that each of the four causes ought to be causally commensurate with its effects. And that which is causally commensurate is more than just sufficient for its effect, it is also necessary for its effect. Sufficiency alone is not enough, then, for any type of causation, and even though there are some ways in which Aristotle is more causally generous than, perhaps, we are, in this way he is more exacting.

TYLER HUISMANN

UNIVERSITY OF COLORADO, BOULDER tyler.huismann@colorado.edu

\section{References}

Allen, James. (2015) 'Aristotle on Chance as an Accidental Cause'. In Mariska Leunissen (ed.), Aristotle's Physics: A Critical Guide (Cambridge, UK: Cambridge University Press), 66-87.

Annas, Julia E. (I982) 'Aristotle on Inefficient Causes'. The Philosophical Quarterly, 32, 3 I I-26. Audi, Paul R. (2013) 'Causation, Coincidence, and Commensuration'. Philosophical Studies, I62, 447-64.

Bailey, D. T. J. (20I4) 'Platonic Causes Revisited'. Journal of the History of Philosophy, 52, I 5-32. Boethius. (200I) Consolation of Philosophy. Trans. J. Relihan. Indianapolis, IN: Hackett Publishing.

Brower, Jeffrey E. (2010) 'Aristotelian Endurantism'. Mind, I I9, 883-905.

Buridan, John. (200I) Summulae de dialectica. Trans. G. Klima. New Haven, CT: Yale University Press.

Charles, David. (1984) Aristotle's Philosophy of Action. London: Duckworth.

Charles, David. (2003). Aristotle on Meaning and Essence. Oxford: Oxford University Press.

Cohen, S. M. (2008) 'Kooky Objects Revisited: Aristotle’s Ontology'. Metaphilosophy, 39, 3-I9.

Charlton, William. (1970) Aristotle: Physics I and II. Oxford: Clarendon Press.

Denyer, Nicholas. (1993) Language, Thought and Falsehood in Ancient Greek Philosophy. New York: Routledge.

Dudley, J. (2012). Aristotle's Concept of Chance: Accidents, Causes, Necessity, and Determinism. Albany, NY: SUNY Press.

Everson, Stephen. (1997). Aristotle on Perception. Oxford: Oxford University Press. 
Fine, Gail. (198I). 'Aristotle on Determinism: A Review of Richard Sorabji's Necessity, Cause, and Blame'. The Philosophical Review, 90, 56I-79.

Frede, Dorothea. (I985). 'Aristotle on the Limits of Determinism: Accidental Causes in Metaphysics E 3'. In Allan Gotthelf (ed.), Aristotle on Nature and Living Things (Pittsburgh, PA: Mathesis Publications), 207-25.

Frede, Dorothea. (I992). 'Accidental Causes in Aristotle'. Synthese, 92, 39-62.

Freeland, Cynthia A. (I99I) 'Accidental Causes and Real Explanations.' In Lindsay Judson (ed.), Aristotle's Physics: A Collection of Essays (Oxford: Clarendon Press), 49-72.

Geach, Peter T. (I956) 'Good and Evil'. Analysis, I7, 33-42.

Hankinson, R. J. (1998) Cause and Explanation in Ancient Greek Thought. Oxford: Clarendon Press.

Hankinson, R. J. (2002) 'Causation and Explanation in Aristotle'. Quaestio, 2, 33-56.

Heinaman, Robert. ( 1985 ) 'Aristotle on Accidents'. Journal of the History of Philosophy, 23, 3 I I24 .

Ide, Harry A. (1993). 'Aristotle Metaphysics vi 2-3 and Coincidences'. Ancient Philosophy, I3, $34 \mathrm{I}-54$.

Irwin, Terence. (1988). Aristotle's First Principles. Oxford: Oxford University Press.

Johnson, Monte R. (2006) Aristotle on Teleology. Oxford: Clarendon Press.

Judson, Lindsay. (I99I) 'Chance and 'Always or for the Most Part' in Aristotle'. In Lindsay Judson (ed.), Aristotle's Physics: A Collection of Essays (Oxford: Clarendon Press), 73-гоo.

Kelsey, Sean. (2004) 'The Argument of Metaphysics vi 3'. Ancient Philosophy, 24, I I9-34.

Kirwan, Christopher. (1993) Aristotle: Metaphysics $\Gamma, \Delta$, and E;. $2 \mathrm{~d}$ ed. Oxford: Clarendon Press. Lennox, James G. (1984) 'Aristotle on Chance'. Archiv für Geschichte der Philosophie, 66, 52-60.

Leunissen, Mariska. (2010) Explanation and Teleology in Aristotle's Science of Nature. Cambridge, UK: Cambridge University Press.

Lorenz, Hendrik. (2015) 'Natural Goals of Action in Aristotle'. Journal of the American Philosophical Association, I, 583-600.

Meyer, Susan Sauvé. ( I992) ‘Aristotle, Teleology, and Reduction’. The Philosophical Review, ro I, 79I-825.

Meyer, Susan Sauvé. (1993) Aristotle on Moral Responsibility. Cambridge, MA: Blackwell.

Matthews, Gareth B. (I982). 'Accidental Unities'. In Malcolm Schofield and Martha C. Nussbaum (eds.), Language and Logos (Cambridge, UK: Cambridge University Press), 223-40.

Matthews, Gareth B. (1990). 'Aristotelian Essentialism'. Philosophy and Phenomenological Research, 50 (Supplement), 25 I-62.

Mueller, Ian. (200I) 'Platonism and the Study of Nature (Phaedo 95eff.)'. In Jyl Gentzler (ed.), Method in Ancient Philosophy (Oxford: Oxford University Press), 67-90.

Oddie, Graham J. (2013) 'An Argument against Commensurate Truthmakers'. Presented at the 20I3 APA Central Division Meeting, New Orleans, LA. February 23, 2013.

Peramatzis, Michail. (20 I I) Priority in Aristotle's Metaphysics. Oxford: Oxford University Press.

Ross, W. D. (1936) Aristotle's Physics. Oxford: Clarendon Press.

Rossi, Gabriela. (20I I) El azar según Aristóteles: Estructuras de la causalidad accidental en los procesos naturales y en la acción. Bonn, Germany: Academia Verlag.

Shields, C. (1999) Order in Multiplicity: Homonymy in the Philosophy of Aristotle. Oxford: Clarendon Press.

Sorabji, Richard. (1980) Necessity, Cause and Blame. London: Duckworth.

Thomson, Judith Jarvis. ( 1997) 'The Right and the Good'. Journal of Philosophy, 94, 273-98.

Williams, C. J. F. (I982) Aristotle's De Generatione et Corruptione. Oxford: Oxford University Press.

Yablo, Stephen. (1992) 'Mental Causation'. The Philosophical Review, IоI, 245-80. 